This is the author's pre-editorial version. Please cite the published article as follows:

Hood, R. (2015) 'Combining phenomenological and critical methodologies in qualitative research', Qualitative Social Work, Epub ahead of print 20 May 2015, doi: 10.1177/1473325015586248

http://qsw.sagepub.com/content/early/2015/05/20/1473325015586248.abstract 


\section{Combining phenomenological and critical methodologies in qualitative research}

\section{$\underline{\text { Abstract }}$}

Interest in qualitative methodologies has grown over recent decades, encouraged by alternative research paradigms in the critical and postmodernist tradition. The array of interpretative frameworks now available to qualitative researchers suggests a potential for pluralist study designs that are not widely employed at present. Drawing on doctoral research in the field of child protection, this paper explores the scope for combining two such frameworks: interpretative phenomenological analysis (IPA) and critical discourse analysis (CDA). It is argued from a critical realist perspective that these methodologies pose different but complementary questions about a given research topic. Within an integrated study design, they can provide a dual lens with which to explore qualitative information, which is interpreted both as lived experience and discursive practice. Textual examples are used in order to show how separate sets of findings are generated using IPA and CDA, and how these may usefully inform each other. The paper proceeds to discuss some broader issues about how researchers produce and interpret qualitative information.

Key words: mixed methods, phenomenology, discourse analysis, critical realism, complexity, 


\section{$\underline{\text { Introduction }}$}

Qualitative research has a long history within social work, and social science in general, even if it has often been forced to justify its 'scientific' credentials amidst a dominant paradigm of positivist inquiry (Agger, 2006, Morris, 2006). Associated with this growing acceptance and respectability has been an increasing array of methods and approaches, enriched by 'methodological borrowings' (Gough, 2012) from other fields such as psychology, anthropology and literary theory. What this offers to the field of social work is ever greater scope to create innovative study designs within the qualitative tradition. This paper will seek to contribute to such innovation by outlining how two different qualitative methodologies, interpretative phenomenological analysis (IPA) and critical discourse analysis (CDA), were combined in a doctoral study of complexity in child protection. The overall approach draws on a critical realist perspective, which has gained increasing acceptance among researchers in the social sciences (Collier, 1994, Danermark et al., 2002, Sayer, 2010). What will be argued in the first part of this paper is that critical realism offers an ontological and epistemological framework that can sustain a pluralist approach to qualitative methodology, allowing researchers to make use of the creative tension that exists between different methods and approaches.

Having made this argument, the key issue to be explored is whether and in what ways might adopting a pluralist approach add to our knowledge of a given topic, compared to the adoption of a single framework of inquiry. In the process, a series of broader questions are invoked about 
the process of gleaning knowledge from qualitative information. For example, one premise commonly accepted by qualitative researchers is that knowledge is shaped to some degree by the interpretative lens employed to decipher that information (Smith et al., 2009). Does this not imply, even if it is possible to achieve a theoretical 'saturation point' within one framework of analysis, such as grounded theory (Charmaz, 2014), that new knowledge may be added by switching our framework? For example, a given interview transcript might yield information about the participant's personal or professional life story, the significance of certain experiences, the influence of political ideologies or cultural tropes, examples of contemporary language use, or the performance of an interviewee's role. Usually researchers are interested in one or other of these options for interpretation, and try to gear the interview around it. But why not use more than one interpretative lens, if doing so suits the purposes of our research?

The last point is an important one. What will be argued here is a case for methodological pluralism, not a relativistic free-for-all. One term of reference is the familiar concept of triangulation. Findings may have greater depth, as well as plausibility, if they draw on results obtained from more than one perspective. Employing more than one method may carry out a similar function to employing more than one researcher - perhaps giving us more confidence in what we find out, but also helping us to find out more. In the quest for meaning in qualitative information, not only do researchers have many options at their disposal but they can make deliberate and increasingly refined choices about their options. This is not an insignificant benefit, considering that the work involved in obtaining qualitative information is itself often the endpoint of a lengthy and bureaucratic process of acquiring funding, navigating ethical and 
research governance procedures, and negotiating access to research sites. In short, having gone to so much trouble to obtain our information, we should try to get the most out of it!

'Mixed methods' study designs combining qualitative and quantitative methods are already common in applied research, although they have also been criticised for relegating qualitative information to 'a largely auxiliary role in pursuit of the technocratic aim of accumulating knowledge of "what works"' (Howe, 2004, cited in Denzin and Lincoln, 2005). Such designs are consistent with a pragmatist approach, in that researchers are not strait-jacketed by prior assumptions regarding the nature of reality or truth and are able to focus instead on what best suits the purpose of the research and on the desired consequences (Cherryholmes, 1992). Elsewhere, Danermark et al. (2002) show how quantitative and qualitative methods can both make sense as part of a critical realist approach to social research. It is in this pluralist vein that the current paper is situated. It is nonetheless important that extending the scope of meaningful interpretation should not imply a descent into arbitrary eclecticism or relativism. Critical realism does involve some ontological and epistemological assumptions, which in Bhaskar's terms serve as a 'philosophical underlabouring' for the scientific investigation of society.

\section{Methodological pluralism within a critical realist framework}

Critical realism is associated with the early work of Roy Bhaskar $(1979,2008)$ and its applications within the social sciences (e.g. Sayer, 2010, Archer, 1995). Bhaskar proposes a 
stratified ontology that differentiates between three layers of reality: the empirical (what we know through our senses), the actual (all events, including those we do not know about) and the real (underlying causal mechanisms that generate events). Events are the result of causal mechanisms operating in open systems, which interact and interfere with each other unless they are deliberately isolated (e.g. in the form of an experiment). Because of this constant feedback and cross-interference, the 'rules' governing cause and effect in open systems become inherently unpredictable in their outcomes. In the physical world of complex systems, this makes predicting behaviour an imprecise science, although not entirely chaotic (Byrne, 2009, Hood, 2012).

The task of identifying causal mechanisms becomes even more difficult when it comes to social behavior and events. This is partly due to the greater complexity of interactions, but also because of the transformational nature of human agency, which both produces and reproduces social structures and processes. For researchers, there is a 'double hermeneutic' of interpreting other people's interpretations (Danermark et al., 2002), so we may never arrive at an objectively 'true' picture of reality. However, this is not to say that knowledge is simply determined by theory. As Bhaskar reminds us, in realist terms there is always an 'intransitive' object of science that is independent of our 'transitive' scientific account of it (2008: 21). This means that we cannot equate our theories with the reality they purport to describe, but it also suggests that some theories have more explanatory power and practical validity than others. In other words, while social research can aim at explanation, and make generalising claims that go beyond understanding the idiographic account, it is not possible to establish universal social laws (Byrne, 2009). 
It will therefore be apparent that critical realism offers a critique of positivist science, which is often associated with quantitative approaches to social research, but also of the strong constructivist position that is associated with qualitative approaches. Happily for social researchers, this does not require them to consign all of their tried and trusted methods to a realist dustbin and start from scratch. On the contrary, critical realism is intended to provide an underlying philosophical framework rather than methodological prescription. The question of whether a particular method is appropriate will therefore depend on its role within the study design, within which are embedded critical realist principles such as (non-Humean) assumptions about cause and effect in social systems. For example, Danermark et al (2002) have set out an integrative approach to social research that allows for a combination of quantitative and qualitative methods within a critical realist framework. Elsewhere, Fairclough (2010) has drawn on critical realism in his version of critical discourse analysis (CDA), in order to explore language, or 'semiosis', as a constitutive element of the social practices that mediate between structure and process. In doing so, he notes that his approach does not entail a rejection of hermeneutics, but rather an acknowledgement that 'hermeneutics by itself cannot provide an adequate explanation of social phenomena' (Fairclough, 2010: 218). On this basis, hermeneutic verstehen and positivist erklaren are understood as 'not so much antithetic as complementary' (2010: 219), allowing scope for a productive dialogue between diverse social theories.

Given that this paper is concerned with advancing a pluralist approach along these lines, it is worth asking what aspects of a social phenomenon might require a dialogue between different qualitative methods. A reference point here is the integrative approach outlined by Saukko 
(2005) in relation to cultural studies, which in her view creatively combines three distinct perspectives:

'[I]t combines a hermeneutic focus on lived realities, a (post)structuralist critical analysis of discourses that mediate our experiences and realities, and a contextualist/realist investigation of historical, social and political structures of power' (Saukko, 2005: 343).

Saukko argues that the philosophical and political tensions between these approaches can be addressed by regarding them as different 'validities', or modes of interpretation and analysis, which should be complementary and mutually reinforcing. A study that sets out to explore and understand a particular lived experience, such as anorexia, for example, can be enriched by also addressing the discourses and social processes that help to shape it, and which individual understandings in turn help to reproduce, transform or subvert. Equally, a study that attempts to carry out a deconstructive analysis of a given belief system can benefit from a phenomenological sensitivity to people's own accounts, so as not to 'reduce the local experiences to props for social theories' (Saukko, 2005: 345). Moreover, reflexive and dialogic forms of research are not self-sufficient but must be situated in the context of broader social processes and structures.

Saukko's 'integrative approach' emphasises the complementary nature of hermeneutic and critical forms of analysis. They are conceived as distinct qualitative lenses, designed to explore different facets of a given topic of study without reinventing or distorting it. This approach lends itself well to the idea of methodological pluralism within a critical realist framework. An array of methods may be required to identify a phenomenon's necessary (internal) relations of 
structure and mechanism, as well as recognising the influence of contingent (external) relations with other phenomena (Sayer, 2010; Danermark et al., 2002). The intensive exploration of a phenomenon will therefore need to examine not only how it is experienced and perceived by the social participants who give it meaning, but also the structural relations through which those meanings are produced. What this suggests is a pluralist approach that can complement a phenomenological emphasis on lived experience with a critical focus on structural context. The distinctiveness of each methodological approach can then be harnessed as a creative dialogue between different modes of analysis.

In what follows, it is proposed to illustrate such an approach through the consideration of two separate but interlinked methodologies: interpretative phenomenological analysis (IPA) and critical discourse analysis (CDA). The study design shown below in Table 1 is adapted from research conducted by the author on the topic of 'complexity' in child protection work.

Insert Table 1 here

Table 1: An example of combining IPA and CDA in a qualitative study

Table 1 shows how different aspects of an overall topic can be formulated as research questions that lend themselves to particular qualitative methodologies. In this study, the use of IPA aimed to explore what practitioners (social workers and other professionals) experienced as complex in a particular case. Correspondingly, the use of CDA aimed to explore how 
practitioners constructed their ideas about complexity through their use of language, or 'discursive practices' (see below). Semi-structured interviews were used to obtain information that was suitable for analysis from both methodological perspectives, i.e. there was no need to gather 'separate' data for each. The rationale for employing this approach, as argued above, was that integrating the findings from IPA and CDA would shed light on the phenomenon of complexity in this particular context. Before considering this rationale on its own grounds - the key issue for this paper - the principles and applications of IPA and CDA will briefly be described.

\section{Interpretative phenomenological analysis (IPA)}

IPA was originally developed for qualitative research into the psychology of health and illness (Biggerstaff and Thompson, 2008, Shaw, 2001, Willig, 2008). It aims to explore the unique meanings that people assign to a certain experience, as well as examine how those meanings relate to the person's individual and cultural context, and to the experiences of others (Shaw, 2001). The terminology refers to a philosophical grounding in both phenomenology and hermeneutics. A phenomenological method involves 'understanding personal lived experience and thus with exploring persons' relatedness to, or involvement in, a particular event or process' (Smith et al., 2009: 40). There is also a hermeneutic emphasis in IPA, which relates to the double act of interpretation necessary to get an 'insider's perspective' on the phenomenon in question. In other words, researchers are people trying to make sense of people trying to 
make sense of their own experiences. For example, Smith et al. (2009) apply the idea of the 'hermenutic circle' to the research process, pointing out that it rarely (if ever) involves a simple, linear movement from data to results. Instead, they posit a reflexive and dynamic process of engagement: with the researcher's own aims, theories, and preconceptions, as well as with participants and their accounts of lived experience.

IPA lends itself to qualitative research that is interested in how people understand and attach significance to their experience of a particular phenomenon, and in drawing out the unique and shared elements of that experience. In the doctoral study outlined above, for example, IPA was used to examine complexity as a phenomenon that was experienced by a variety of professionals working together on a child protection case (see Hood, 2014a). The methodological procedures of IPA are described in detail by Smith et al. (2009). Qualitative information is usually collected via semi-structured interviews, although unstructured interviews may also be conducted by more experienced researchers. The sample of participants is usually quite small due to the detailed and intensive nature of the analysis. Interviews are generally recorded and anonymised transcripts produced for analysis. The process of analysis for an IPA study is based on an idiographic commitment to work one case at a time, one step at a time, and is largely inductive, drawing out 'the most interesting and most important aspects' of the participant's account (Smith, 2009: 99). After this has been done for all cases, the researcher looks for patterns across cases, recognising superordinate themes but also 'unique idiosyncrasies' that are revealing of individual experiences. 
Like all research methods, IPA has its conceptual and practical limitations. Willig (2008: 66) raises the issue of whether language should be seen as representative or constitutive of people's efforts to make sense of the world. For example, IPA's quest to explore an 'insider's perspective' relies on the participant being able to describe their subjective understanding of a phenomenon through language. In this respect, Smith et al. (2009: 196) note that IPA complements the approach taken by discourse-oriented methodologies, since the former provides insights into people's lived experience, while the latter focuses on 'the resources available to the individual in making sense of their experience'. A similar approach is taken by Johnson et al. (2004), who contrast 'Foucaldian' discourse analysis with IPA. Again, such arguments indicate the creative possibilities opened up by questioning the textual account provided by the insider perspective. Although elements of a critical stance are certainly inherent in the 'interpretative' side of IPA, the analytical tools available to the researcher are broadened by variants of discourse analysis such as CDA.

\section{Critical Discourse Analysis (CDA)}

Critical discourse analysis (CDA) has a diverse theoretical background, mainly in applied linguistics and social theory (Locke, 2004, Weiss and Wodak, 2003, Fairclough, 2009). It is particularly associated with the work of Norman Fairclough (e.g. 2003, 2010), and is usually concerned with the connection between language or language use, what Fairclough calls 'semiosis' (2010: 202), and social structures and practices. CDA often seeks to examine and 
critique aspects of ideology and power that are embedded in conventional, institutional or 'common-sense' uses of language. Language is about more than just representation (e.g. of things, or thoughts) as it is also a constitutive social practice, i.e. discourse. There is a further distinction between a general sense of discourse as 'language use in speech and writing' (Fairclough and Wodak, 1997: 258) and a more specific concern with 'sense-making stories' (Locke, 2004: 5) that circulate in society and influence how people understand and perceive the world. According to Fairclough (2010: 95-96), 'discursive events' are particular instances of language use, which produce texts (written, verbal or visual) for the purpose of conveying meaning to others. He also defines 'genres' as the use of language associated with a particular social activity. For example, the characteristic manner in which doctors discuss a medical case with each other could be analysed as a genre that is composed of particular discursive practices, e.g. use of impersonal pronouns, latin terminology, and so on. This genre of 'case presentation', in combination with other genres and discursive practices common to the way doctors 'talk', can then be said to contribute to a distinctive 'medical discourse' (Anspach, 1988). Furthermore, texts tend to be constituted from a variety of discourses and genres, an attribute that Fairclough calls 'intertextuality'.

As a research method, CDA is chiefly concerned with the analysis of texts, in order to deconstruct the links between discursive and social practices. Texts may be written or oral and can include visual or observational data, or transcripts of verbal conversations. In the study described earlier, the use of CDA related to how complexity was constructed in professional discourse about working together on complex cases. The texts in question were the transcripts of interviews with professionals. There are many different ways of actually carrying out 
discourse analysis, but the approach used in this study was adapted from the framework set out by Fairclough (2003). The method essentially consists of a detailed breakdown of different textual elements, which are in turn linked to various analytical concerns (Hood, 2014). For example, a consideration of intertextuality will look at how different voices and perspectives are brought into the text, and they support, balance or even contradict the voice of the speaker. This in turn could indicate how the idea of difference is treated within the text, not only differences of opinion between people but also people's awareness and acceptance of divergent or competing perspectives. In another example, the analysis of identification within the text will look at the interplay between the social and personal aspects of identity, and how this interaction is enacted in the style of a particular text.

CDA has been subjected to some criticism as a research method, mainly centred on the soundness of its theoretical foundations (Hammersley, 1997) and its claims to produce valid knowledge (Widdowson, 1995). For example, Widdowson charges CD analysts with 'replacing argument with persuasion and confusing cogency with conviction' (1995: 171). In considering some of these objections, Haig (2004) notes that many of the foremost exponents of CDA, including Fairclough, sometimes omit details of how texts were sampled, do not formally describe the detailed textual analysis that their method entails, and rely on skilful interpretations of texts for the effectiveness of their account. It could be argued that by using CDA as part of a pluralistic methodological approach, some of these limitations might be addressed - for example by clarifying the procedures used in obtaining and analysing the texts 
used for the analysis. The following section will work through some examples to show how qualitative information may be analysed by combining IPA and CDA approaches.

\section{Combining IPA and CDA}

The author's study of complexity in child protection work (Hood, 2013) was carried out in an outer London metropolitan borough. Two child protection cases were selected with the help of the lead agency for children's social care. Inclusion criteria were that each case should involve current child protection plans, a professional network with diverse representation from the main child welfare agencies, i.e. health, education and social work, and an assessment of multiple, interrelated needs. Ethical authorisation for the study was obtained, along with research governance approval from the agencies and informed consent from participants. Two rounds of semi-structured one-to-one interviews were then carried out with a total of 17 practitioners over a period of four months. All of the interview transcripts were then subjected to two rounds of analysis using IPA and CDA, with the process recorded on qualitative research software (Atlas.ti).

A full description of the IPA methodology used for this study can be found in (Hood, 2014). Its ultimate aim was to capture what was shared but also what was divergent in the way people make sense of their experiences. Superordinate themes were therefore grouped around clusters of related meaning, while also ensuring representativeness throughout the body of transcripts. This largely inductive form of theorising was then supplemented with a deeper level 
of interpretation to move beyond the descriptive, for example by using the micro-analysis of a particular extract to explore themes emerging from the interview as a whole. Some of these extracts are reproduced below in order to illustrate the process. Using IPA, the participant interviews created a picture of complexity as a lived experience, enabling the researcher to describe what it meant for these practitioners to work on a complex case, to compare and contrast their experiences, and to ascertain what complexity signified in this interprofessional context.

One of the principal themes emerging from the analysis was about the perception of causality (cause and effect). In these cases, practitioners experienced causality as an unpredictable and volatile process. They found it difficult to attribute underlying reasons to the problems and crises they were dealing with. In their efforts to decipher what was going on, interesting parallels emerged between personal identities and impersonal events:

For us it was incredibly frustrating when those moments of crisis arose... they boiled up into this kind of volcano-type eruption and then nothing occurred, nothing changed - and so it kind of then receded and just carried on again bubbling under the surface until we hit crisis point again.'

School nurse, Case 1.

'He's such a potential volcano. Because you don't know whether he's going to go completely off the rails again or whether he will actually be really chuffed with himself.'

Fire prevention officer, Case 2. 
These quotes illustrate the treatment of qualitative information from an IPA perspective. Both professionals are drawing on the same image of the volcano to describe a phenomenon that is volatile and uncontrollable - experienced in the first example as a pattern of events, and in the second example as the behaviour of a child. The association of causality is with the powerful, unpredictable and incomprehensible forces that produce the periodic eruptions of a volcano. One further interpretation, evident in the second quotation, is the notion of the 'unstable' child, who is temperamentally explosive and therefore defies some of the conventional expectations of adults, e.g. that children should be malleable, controllable - or at the very least knowable. In contrast, the children at the centre of both these cases were often perceived as being outside of the control of adults. In their interactions with others, their behaviour could switch quite quickly, e.g. between likeability and aggression, depending on context or behavioural 'triggers'. This shift in attribution - from unpredictable causal forces to volatile characteristics and unstable relationships - was emblematic of the way complexity was experienced in interprofessional casework.

Using CDA throws a different light onto the language used by participants to describe their experiences. It enables the researcher to identify characteristics of different discourses that help to frame and shape people's accounts, and to focus on issues of power and difference. The approach used in this study (see Hood, 2014b, for details) was adapted from the framework set out by Fairclough (2003). The method essentially consists of a detailed qualitative analysis based around different textual elements, which are in turn linked to six analytical concerns: intertextuality, assumptions, representation of events, styles, and interdiscursivity. Using these categories, each interview transcript was analysed in turn in order to draw out different aspects 
of language use in relation to the research topic. The analysis of intertextuality, for example, concerned the way in which different voices and perspectives were combined or otherwise treated within the text. Initial themes for each transcripts were then grouped into what Fairclough (2010) calls 'orders of discourse', which are characterised by a set of distinctive voices, assumptions, identities, and representations of the world.

One order of discourse emerging from the CDA findings was called the 'clinical perspective'. This had to do with the way practitioners referred to their identity as experts, for example in when talking about interactions with service users or colleagues. While 'clinical' talk enabled professionals to categorise and explain certain types of behaviour, in an interprofessional context it was also bound up with claims to expertise and the practitioner's own place in a hierarchy of professional judgement:

'I think in this particular case I felt that he did have I think both ADHD and social communication difficulties - that they were contributing factors but not necessarily the only factors that would be relevant.'

CAMHS psychiatrist, Case 1.

'I might not be a psychiatrist - but I work with this child on a far more intense level than [the psychiatrist]. So [he has] got the expertise about psychological conditions, I've got the expertise about this child, so how about we work together on that one? But I do get the feeling sometimes that it's a bit like: "Well you are a social worker, you don't know what you're talking about."' 
Social worker, Case 1.

These two quotes show claims to clinical expertise being made in different ways. The first quote, from the psychiatrist at the Child and Adolescent Mental Health Service (CAMHS), stresses both the probabilistic nature of diagnosis ('contributing', 'not necessarily') and its subjectivity ('I felt', 'I think'). The diagnosis is presented as the clinician's view on the key difficulties out of a range of possible causes (which are not eliminated and remain in the background). The emphasis is on a particular kind of medical-scientific knowledge, i.e. causal 'factors' that are known to potentially play a part in shaping behaviour. The clinician is the central figure, whose expertise is around weighing up the information received from family members and other professionals in the light of medical knowledge. In contrast, the social worker in the second quote emphasises a more dialogical form of assessment, as well as the validity of different types of knowledge. She constructs a hypothetical discussion between herself and the psychiatrist, positing diagnosis as a collaborative process in which the social worker's 'expertise about the child' is placed on an equal footing with the clinical expertise of the psychiatrist. Her point, of course, is that in this case (and others) this has not happened, and instead she has experienced an unequal power dynamic in which her expertise is not respected. The intersection and contest between different types of expertise, including that of service users, as well as ideas about how expertise should be organised and directed towards specified needs, was integral to the way that complexity was talked about by professionals.

Taken together, the two sets of findings produced by these analytical approaches allowed complexity to be understood as a phenomenon that was both experienced and constructed in 
discourse. From an IPA perspective, complexity for practitioners was perceived in terms of the challenges and dilemmas of working with others on 'this' complex case. From a CDA perspective, their experiences were connected to the socio-linguistic practices through which they understood their work and identified themselves as practitioners. For example, the experience of lacking control over events was found to be partly rooted in practitioners' inability to frame the situation within conventional narratives of client problematic and professional efficaciousness, or of clinical assessment and evidence-based intervention. Complexity not only undermined conventional patterns of cause and effect, and therefore perceptions of control, but also highlighted the relationships between professionals, and between professionals and service users. Elsewhere in the literature, these relationships have often been analysed in psychodynamic terms, as for example when patterns of interaction within the family are 'acted out' in the professional network (Granville and Langton, 2002, Woodhouse and Pengelly, 1991), or experienced symptomatically by the individual practitioner (Cartney, 2011: 22). Here systemic behaviour was analysed as a dialectical interplay between causal and social complexity (Hood, 2012), which means that the non-linear dynamics of complex systems were seen to feed into the social process of constructing knowledge about the world.

Looked through the dual lenses of phenomenology and discourse, social complexity does not simply imply a connection between the interprofessional network and the family, but rather an reflexive interconnection. It points to the co-constitutive nature of the 'double hermeneutic' in which practitioners are engaged. On the one hand, in striving to understand the child/family/case, professionals impose categories of knowledge and identification onto service 
users. At the same time they are being understood, as professionals/people/service, and this in turn shapes how they conceptualise their own activities and identities. Problems do not just present themselves for professionals to solve; they are presented, discussed and enacted by people, whose objectives and intentions may not be evident or even consciously pursued. Likewise, interventions are not administered, as a medicine or treatment might be; they are social transactions willingly or compulsorily entered into by their participants. Therefore complexity is not simply an aspect of the problematic situation, i.e. a separate problem to be solved by professionals, but rather emerges from the entangled state in which the practices of all those concerned are being negotiated. The complex case, in other words, is an emergent structure whose activity cannot be managed as a technical operation. By implication, this raises the question of how interprofessional networks should be organised to manage complexity conceived as such (Hood, 2014c).

\section{Implications for social work research}

One implication of the pluralist methodology advocated here is that the systematic deployment of a critical perspective through CDA might offer a way of connecting the 'insider's perspective' gained through IPA to the contextual issues that are identified in the initial literature review and revisited in the discussion of findings. For example, one question examined by the research described above was whether child protection policies in the UK lacked an adequate understanding of the complexity of frontline work and consequently were relying too heavily on technocratic solutions delivered by so-called 'expert systems'. The challenge in making such an argument, as so often in qualitative research, was to connect the detailed information obtained 
through a limited number of in-depth interviews to Saukko's 'realist/contextualist investigation', i.e. the broader context and rationale for undertaking the research in the first place. In this respect, CDA also created space for a positive critique in the sense of exploring the possibilities of transformation that were evident in practitioners' accounts. This critique could then be applied to the institutional context in which professionals were working, in the form of a commentary on the 'team around the child' and the various possibilities for collaboration that exist in that context.

It is also worth considering whether the pluralist approach considered here, in its effort to combine critical depth together with fidelity to participants' lived experience, make it particularly suited for qualitative research in the field of social work. Professional training and ethical standards in social work tend to emphasise both of these elements, with a respect for the dignity, expertise and viewpoint of others allied to a close regard for potential sources of inequality and oppression in social relationships. Not coincidentally, there is a thriving tradition of studies with an avowedly critical orientation, perhaps exemplified by action research designs (Greenwood and Levin, 1998), as well as a strong current of postmodernist and social constructionist research in the field of social work (Chambon et al., 1999). In taking our cue from these developments, the challenge is to avoid the pitfalls of methodological tribalism, awarding terms such as 'critical' or 'phenomenological' the status of 'honorific titles' (Hammersley, 2005) that are reserved for certain categories of research topic or study design. When they are combined in a systematic way, these methodologies can exploit the manifold uses of qualitative information, making it clear what interpretative framework is being applied to the 'text' in question. In turn, the findings can be used to hold up a kind of critical mirror to 
what has been said elsewhere in the literature, and so contribute to theoretical debates, policy discussions as well as the significance of everyday experience.

A final question is how these methodological issues relate to applied research, including the evaluation of programmes and interventions. It is an important issue for social work, a profession long under pressure to become more 'evidence-informed'. As noted earlier, there is a methodological pluralism often found in applied research that aims to integrate quantitative with qualitative information. From a critical realist standpoint, both types of evidence can yield an insight into how and why interventions work, whereas a positivist approach would be more likely to see the former as evidence of causal effectiveness and the latter as idiographic detail. To take a recent example, the ideas in this paper are both in congruence and in conflict with the realist approach of Pawson (2013), who argues that it is the factors driving complexity that should be targeted by evaluation research. On the one hand, Pawson concurs with the use of pluralist methods to identify mechanisms of change, as well as the contextual factors that affect those mechanisms, as this allows the research to explore how particular configurations lead to particular outcomes. On the other hand, he is very sceptical about the process of Bhaskarian critique, regarding it as a thinly veiled 'descent into the arms of politicised inquiry' (Pawson, 2013, p.62). The relevance of critical methodologies for evaluation research is therefore a controversial implication, and one that needs further exploration. Nonetheless, the case for pluralism made here would suggest that a research method such as CDA can yield relevant knowledge about a phenomenon without the need for overt political or 'emancipatory' goals. As always, what matters is that the research is undertaken in a systematic and transparent way, and within a defined framework of inquiry. 


\section{Conclusion}

Critical and constructionist orientations have been generally presented as 'alternative paradigms' in the literature on social work research (Morris, 2006) and qualitative research in general (Guba and Lincoln, 2005). This paper has presented a pluralist approach aiming to harness some of those distinctions, using the ontological and epistemological principles of critical realism as an overarching framework. It has been argued that the benefits of such an approach include a more comprehensive picture of the topic under investigation, and a way of linking ideographic detail more clearly to broader contextual issues. Ultimately, the interpellation of hermeneutics and critique aims to add explanatory value to the eventual findings, whatever the topic. Nonetheless, it should be clear that there are many different ways of designing a pluralist methodological approach to qualitative research, and what has been described here is just one possible combination of methods. Nor should it be necessary to adopt a critical realist framework, if other orientations suit the research better. It would be interesting, for example, to consider all the various tools at the disposal of social constructionist researchers to decipher narratives, transcripts, stories, observations, ethnographies, and so on. In the end, as long as they are clear and convincing in their use of methodological pluralism, qualitative researchers can always choose do more with their information. 


\section{$\underline{\text { References }}$}

Agger, B. (2006). Critical Social Theories. Paradigm: Boulder, CO.

Anspach, R. (1988). 'Notes on the Sociology of Medical Discourse: The Language of Case

Presentation'. Journal of Health and Social Behaviour, 29(4), 357-375.

Archer M. (1995) Realist Social Theory: the morphogenetic approach. Cambridge: Cambridge University Press.

Bhaskar, R. (1979). The Possibility of Naturalism: A Philosophical Critique of the Contemporary Human Sciences. Harvester Press: Brighton.

Bhaskar, R. (2008). A Realist Theory of Science. Verso: London.

Biggerstaff, D. \& Thompson, A. R. (2008). 'Interpretative Phenomenological Analysis (IPA): A Qualitative Methodology of Choice in Healthcare Research'. Qualitative Research in Psychology, 5(3), 214-224.

Byrne, D. (2009). 'Complex realist and configurational approaches to cases'. In Byrne, D. \& Ragin, C. (eds.), The Sage Handbook of Case-Based Methods. London, Sage.

Cartney, P. (2011). 'Consolidating practice with children and families'. In Cocker, C. \& Allain, L. (eds.), Advanced Social Work with Children and Families. Exeter, Learning Matters Ltd. 
Chambon, A., Irving, A. \& Epstein, L. (1999). Reading Foucault for social work. Columbia University Press: New York.

Charmaz, K. (2014). Constructing grounded theory. Sage: London.

Cherryholmes, C. H. (1992). 'Notes on Pragmatism and Scientific Realism'. Educational Researcher, 21(6), 13-17.

Collier, A. (1994). Critical Realism: An Introduction to Roy Bhaskar's Philosophy. Verso: London.

Danermark, B., Ekstrom, M., Jacobsen, L. \& Karlsson, J. C. (2002). Explaining society: critical realism in the social sciences. Routledge: Abingdon.

Denzin, N. \& Lincoln, Y. (eds.) (2005) The Sage Handbook of Qualitative Research: Third Edition, Thousand Oaks: CA, Sage.

Fairclough, N. (2003). Analysing Discourse: Textual analysis for social research. Routledge: London.

Fairclough, N. (2009). 'A dialectical-relational approach to critical discourse analysis in social research'. In Wodak, R. \& Meyer, M. (eds.), Methods of Critical Discourse Analysis. London, Sage.

Fairclough, N. (2010). Critical Discourse Analysis: The Critical Study of Language. Pearson Education Limited: Harlow.

Fairclough, N. \& Wodak, R. (1997). 'Critical discourse analysis'. In van Dijk, T. (ed.) Discourse Studies: A Multidisciplinary Introduction. Vol. 2., London, Sage. 
Gough, N. (2012). 'Complexity, complexity reduction, and 'methodological borrowing'in educational inquiry'. Complicity: An International Journal of Complexity and Education, 9(1),

Granville, J. \& Langton, P. (2002). 'Working across boundaries: systemic and psychodynamic perspectives on multi-disciplinary and inter-agency practice'. Journal of Social Work Practice, 16(1), 23-27.

Greenwood, D. \& Levin, M. (1998). Introduction to action research: Social research for social change. Sage: London.

Guba, E. G. \& Lincoln, Y. (2005). 'Paradigmatic controversies, contradictions and emerging confluences'. In Denzin, N. \& Lincoln, Y. (eds.), The Sage Handbook of Qualitative Research: Third Edition. Thousand Oaks: CA, Sage, pp. 191-217

Haig, E. (2004). Some Observations on the Critique of Critical Discourse Analysis [Online]. Available: http://www.lang.nagoya-u.ac.jp/proj/genbunronshu/25-2/haig.pdf [Accessed 02/08/2012].

Hammersley, M. (1997). 'On the foundations of critical discourse analysis'. Language and Communication, 17(3), 237-248.

Hammersley, M. (2005). 'Should Social Science Be Critical?'. Philosophy of the Social Sciences, 35(2), 175-195.

Hood, R. (2012). A critical realist model of complexity for interprofessional working. Journal of interprofessional care, 26(1), 6-12. 
Hood, R. (2013) Complexity and interprofessional working in children's services. PhD Thesis, Royal Holloway, University of London, UK.

Hood, R. (2014), How professionals talk about complex cases: a critical discourse analysis. Child \& Family Social Work. Epub ahead of print 9 Jan 2014. doi: 10.1111/cfs.12122

Hood, R. (2015a). A socio-technical critique of tiered services: implications for interprofessional care. Journal of interprofessional care, 29(1), 8-12.

Hood, R. (2015b). How professionals experience complexity: an interpretative phenomenological analysis. Child Abuse Review 24(2): 140-152

Johnson, S., Burrows, A., and Williamson, I. (2004). 'Does my bump look big in this?'The meaning of bodily changes for first-time mothers-to-be. Journal of Health Psychology, 9(3), 361374 .

Locke, T. (2004). Critical Discourse Analysis. Continuum: London.

Morris, T. (2006). Social Work Research Methods: Four Alternative Paradigms. Sage: Thousand Oaks: CA.

Pawson, R. (2013). The science of evaluation: A realist manifesto. Sage: London.

Saukko, P. (2005). 'Methodologies for Cultural Studies: An Integrative Approach'. In Denzin, N.

\& Lincoln, Y. (eds.), The Sage Handbook of Qualitative Research. London, Sage.

Sayer, A. (2010). Method in Social Science: A Realist Approach. Routledge: London. 
Shaw, R. L. (2001). 'Why use interpretative phenomenological analysis in health psychology?'. Health Psychology Update, 10(4), 48-52.

Smith, J. A., Flowers, P. \& Larkin, M. (2009). Interpretative Phenomenological Analysis: Theory, Method and Research. Sage: London.

Weiss, G. \& Wodak, R. (2003). Critical Discourse Analysis: Theory and Interdisciplinarity. Palgrave Macmillan: Basingstoke.

Widdowson, H. G. (1995). 'Discourse analysis: a critical view'. Language and Literature, 4(3), 157-172.

Willig, C. (2008). Introducing qualitative research in psychology (2nd Edition). Open Univesity Press: Maidenhead.

Woodhouse, D. \& Pengelly, P. (1991). Anxiety and the dynamics of collaboration. Aberdeen University Press: Aberdeen. 